\title{
Arterio-bronchial fistula as a complication of post-traumatic subclavian artery pseudoaneurysm: radiological findings and outcome
}

\begin{abstract}
Post-traumatic arterio-bronchial fistula is a rare cause of life-threatening hemorrhage. We present a case of a ten-year-old patient with a post-traumatic subclavian artery pseudoaneurysm complicated by an arterio-bronchial fistula and occlusion of the subclavian artery. The patient was treated with a stent-graft. We present radiological images of the fistula and the evolution of the changes in subsequent follow-up examinations.
\end{abstract}

Key words: pseudoaneurysm, arterio-bronchial fistula, computed tomography

Adv Respir Med. 2019; 87: 110-113

\section{Introduction}

A post-traumatic arterio-bronchial fistula is a rare cause of life-threatening hemorrhage. Emergency intervention is needed and thus requires immediate diagnosis [1-6]. Modern treatment most often involves endovascular procedures. Depending on the caliber and the significance of the involved vessels, embolization or exclusion of the fistula with a stent-graft may be possible $[4,7]$. Multi-slice computed tomography is an especially useful imaging modality in such cases $[2-4,7-10]$. We present a case of a pediatric patient with a post-traumatic subclavian artery pseudoaneurysm complicated by an arterio-bronchial fistula with a hemorrhage into the bronchial tree. We outline the radiological findings and the outcome.

\section{Case report}

the patient was a ten-year-old female who had been treated surgically, using intramedullar
Kirschner wire, to stabilize the fragments resulting from a fracture of the distal part of the left clavicle. Eight weeks following the procedure (nine after the fracture occurred) the patient was admitted to hospital due to bleeding and a dehiscence of the previously healed surgical wound. The site of the bleeding was sutured, the wound closed and the Kirschner wire removed. After subsequent two weeks, the patient was once again admitted because of massive hemoptysis (100-130 ml/24 hours), dyspnea, pain in the left supraclavicular region and increasing symptoms of ischemia of the upper left limb with paralysis of the brachial plexus. On admission, RBC was $3.91 \mathrm{M} / \mathrm{uL}$, WBC 9.27K/uL, hemoglobin $10.7 \mathrm{~g} / \mathrm{dL}$ and hematocrit $31.5 \%$. On CT examination, a tumoral lesion, which was strongly enhanced after contrast administration, was observed in the left lung field. An angio-CT (GE lightspeed VCT) examination was immediately performed revealing a pseudoaneurysm that penetrated into the supraclavicular region and an arterio-bronchial fistula with bleeding into the bronchial tree

Address for correspondence: Ludomir Stefańczyk, Department of Radiology and Diagnostic Imaging, Medical University of Lodz, USK nr 1, Kopcińskiego 22, 90-153 Łódź, Poland, e-mail: stefanczyk_@@wp.pl

DOI: 10.5603/ARM.2019.0017

Received: 02.12 .2018

Copyright (C) 2019 PTChP

ISSN 2451-4934 

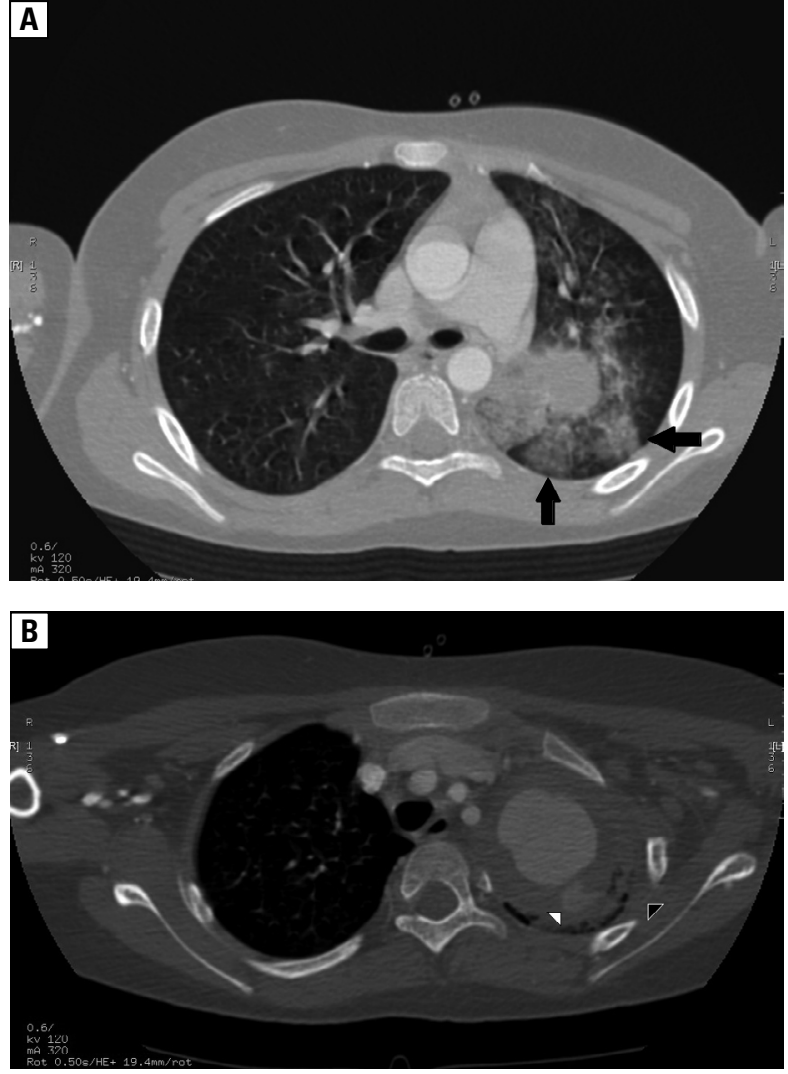

Figure 1. CT scan of arterio-bronchial fistula, intra alveolar haemorrhage; $\mathbf{A}$ - in the area of pseudoaneurysm visible as thickening of the lung parenchyma - ground-glass opacity (black arrows); B - the contrast-enhanced blood in the thrombus in the aneurysmal sac reveals the location of the fistula (white arrow head). The fistula is secondary to pressure damage caused by the pseudoaneurysm to the lung. A clear thickening of the pleura is visible in the top of the lung (black arrow head)

and alveoli (Fig. 1A, B). There was an occlusion of the distal part of the subclavian artery, the axillary artery was being supplied by collateral circulation. During the hospitalization, bleeding into the bronchial tree recurred twice, each time 80-100 $\mathrm{ml}$ of blood was expectorated. Before the procedure RBC was $3.43 \mathrm{M} / \mathrm{uL}$, WBC $9.98 \mathrm{~K} / \mathrm{uL}$, hemoglobin $9.2 \mathrm{~g} / \mathrm{dL}$ and hematocrit $27.9 \%$. The patient was successfully treated using a hemobahn stent-graft, excluding the wide-necked pseudoaneurysm [11]. Antithrombotic therapy (clopidogrel), as well as a three-week course of antibiotic therapy (amoxicillin with clavulanic acid) were instituted. Due to the improving clinical status, the decision of decompression of the hematoma was delayed until the next radiological check -up. In a follow-up CT performed a month after the stent implantation, patency in the subclavian and axillary arteries was confirmed. The sac of the pseudoaneurysm had decreased in size and was not filled with contrast enhanced blood.

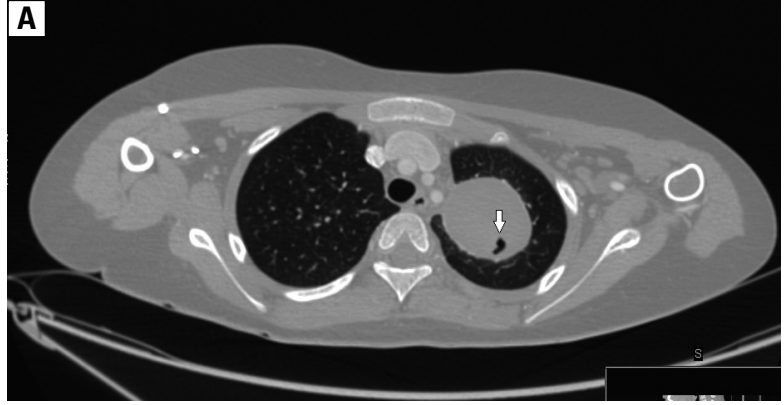

B

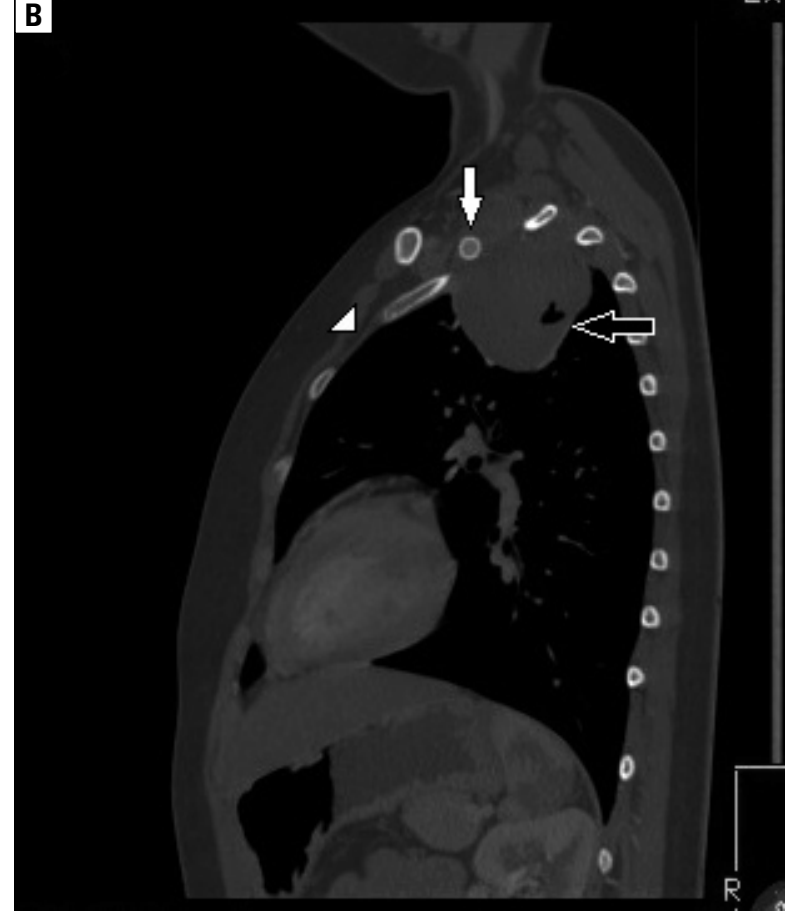

Figure 2. CT scans a month after treatment of the fistula; $\mathbf{A}-$ the gas bubble in the thrombus in the aneurysmal sac confirms the location of the fistula (white arrow). Changes in the pulmonary parenchyma underwent involution; B - involution of changes in pleural lesions (white arrow head). A patent stentgraft in the lumen of the subclavian artery (white arrow). A gas bubble in the aneurysmal sac at the fistula site (black arrow)

The changes around the bronchial tree and lung parenchyma regressed completely (Fig. 2A, B). Laboratory parameters were within normal ranges. Rehabilitation exercises of the extremity were continued. A follow-up radiographic examinationcarried out six months after the procedure showed involution of the hematoma in the lung parenchyma (Fig. 3). The stent-graft patency was confirmed in a USG-CD examination. A HRCT of the lungs was performed nine months after the procedure. Further involution of the hematoma without wall calcification was noted (Fig. 4). The patient did not have any upper respiratory tract infections or require antibacterial therapy during the course of observation following the procedure. Spirometry was normal. 


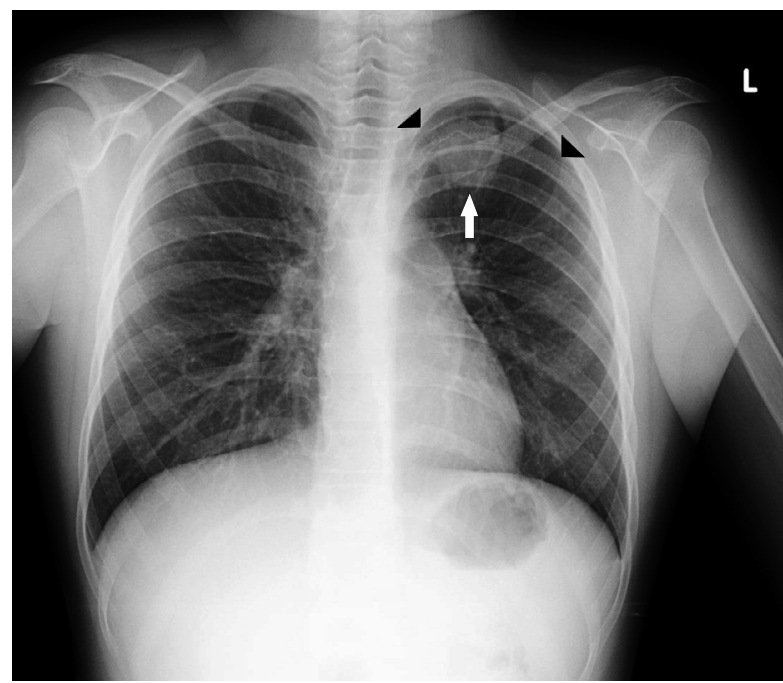

Figure 3. X-ray image 6 months after treatment-involution of the aneurysmal sac (white arrow). Stentgraft in the subclavian artery (black arrows head)

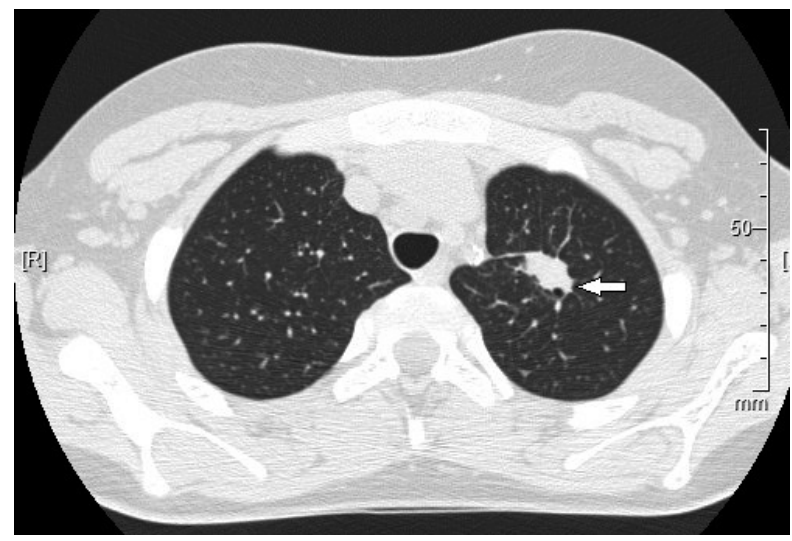

Figure 4. CT scan 9 months after fistula treatment. Changes in the pulmonary parenchyma, pleura and aneurysm sac underwent further involution (white arrow)

\section{Discussion}

A hemorrhage into the bronchial tree with massive hemoptysis is usually the result of a perforation of the pulmonary or bronchial arteries and less commonly the thoracic aorta $[1-3,6]$. Perforation of a pseudoaneurysm of the systemic arteries into the bronchial tree is a very rare and dangerous complication [1, 3, 9]. To our knowledge, another case of a pseudoaneurysm of the subclavian arteries perforating into the bronchial tree has not been previously reported in the literature [11]. In contrast to the frequently reported cases of arterio-bronchial fistulas, which are usually complications of tuberculosis or neoplasms, post-traumatic fistulas can develop rapidly and require a quick diagnosis and intervention $[1,3,6]$. The diagnostic modality of choice is a multi-slice computed tomography that shows both the course of the vessels and the surrounding tissue. This allows for a rapid diagnosis, an image of the regional anatomy, as well as intervention planning, thus replacing the more invasive bronchoscopy and angiography [2-5, 7-10]. Sometimes CT does not show the fistula directly (this was especially common in single-slice CT scanners), and the diagnosis is possible only basing on indirect symptoms $[1,5,9]$. In the presented case, the CT image of the bleeding into the bronchial tree was characterized by hemorrhagic deposits in the alveoli of the left lung as well as in the bronchial tree $[5,10]$. The irregular trickles of enhanced blood in the vicinity of the mural thrombus was indicative of the fistula location. This was confirmed in the follow-up CT examination by air deposits in the cavity of the excluded pseudoaneurysm [5]. Although the damaged artery did not course in the chest wall, pleural thickening was visible in the vicinity [6]. There was a concern regarding the risk of infection in the bronchial tree with the hemorrhage, especially in the region of the aneurysmal sac that was in direct communication with the bronchial tree. Infection would have complicated the treatment and could have resulted in the need for implant removal, and possible limb loss [9]. Therefore, prophylactic antibiotic therapy was employed until healing of the graft and involution of the hematoma were complete. Taking into consideration the patient's and her parents' opinion and the rapidly improving clinical status of the girl, hematoma decompression was not performed.

The literature suggests that post-hemorrhagic ground glass consolidation resolves quickly in the first weeks after the hemorrhage [10]. A follow-up CT examination performed one month after the procedure confirmed the involution of the originally observed interstitial changes, alterations in the alveoli and bronchioles, as well as the thickened pleura. There were no changes suggestive of fibrosis [10]. In subsequent follow-up examinations, the pseudo-aneurysmal sac was seen as a round, well circumscribed shadow, gradually decreasing in size. In the follow-up examination, cavitation of the lung lesion was not observed thanks to the elasticity of the surrounding healthy lung tissue. Follow-up examinations did not reveal any residual impairment of lung function.

\section{Conflict of interest}

The authors declare no conflict of interest. 


\section{References:}

1. Ferretti GR, Choplin RH, Haponik EF, et al. Case report. Aortic pseudoaneurysm with aortobronchial fistula: diagnosis with CT angiography. J Comput Assist Tomogr. 1996; 20(6): 975978, indexed in Pubmed: 8933801.

2. Jeudy J, Khan AR, Mohammed TL, et al. Expert Panel on Thoracic Imaging. ACR Appropriateness Criteria hemoptysis. J Thorac Imaging. 2010; 25(3): W67-W69, doi: 10.1097/ RTI.0b013e3181e35b0c, indexed in Pubmed: 20711032.

3. Kazerooni EA, Williams DM, Abrams GD, et al. Aortobronchial fistula 13 years following repair of aortic transection. Chest. 1994; 106(5): 1590-1594, indexed in Pubmed: 7956427.

4. Keeling AN, McGrath FP, Lee MJ. Interventional radiology in the diagnosis, management, and follow-up of pseudoaneurysms. Cardiovasc Intervent Radiol. 2009; 32(1): 2-18, doi: 10.1007/s00270-008-9440-3, indexed in Pubmed: 18923864.

5. Khalil A, Parrot A, Nedelcu C, et al. Severe hemoptysis of pulmonary arterial origin: signs and role of multidetector row CT angiography. Chest. 2008; 133(1): 212-219, doi: 10.1378/ chest.07-1159, indexed in Pubmed: 17989162.

6. Yoon W, Kim YH, Kim JK, et al. Massive hemoptysis: prediction of nonbronchial systemic arterial supply with chest CT. Radio- logy. 2003; 227(1): 232-238, doi: 10.1148/radiol.2271020324, indexed in Pubmed: 12601194.

7. Yoon W, Kim JK, Kim YH, et al. Bronchial and nonbronchial systemic artery embolization for life-threatening hemoptysis: a comprehensive review. Radiographics. 2002; 22(6): 1395-1409, doi: 10.1148/rg.226015180, indexed in Pubmed: 12432111.

8. Noë GD, Jaffé SM, Molan MP. CT and CT angiography in massive haemoptysis with emphasis on pre-embolization assessment. Clin Radiol. 2011; 66(9): 869-875, doi: 10.1016/j. crad.2011.03.001, indexed in Pubmed: 21658690.

9. Milano A, De Carlo M, Mussi A, et al. Aortobronchial fistula after coarctation repair and blunt chest trauma. Ann Thorac Surg. 1999; 67(2): 539-541, indexed in Pubmed: 10197688.

10. Revel MP, Fournier LS, Hennebicque AS, et al. Can CT replace bronchoscopy in the detection of the site and cause of bleeding in patients with large or massive hemoptysis? AJR Am J Roentgenol. 2002; 179(5): 1217-1224, doi: 10.2214/ ajr.179.5.1791217, indexed in Pubmed: 12388502 .

11. Stefańczyk L, Czeczotka J, Elgalal M, et al. A large posttraumatic subclavian artery aneurysm complicated by artery occlusion and arteriobronchial fistula successfully treated using a covered stent. Cardiovasc Intervent Radiol. 2011; 34 Suppl 2: S146-S149, doi: 10.1007/s00270-010-9959-y, indexed in Pubmed: 20697709. 